\title{
Article
}

\section{The Relationship among Cohesion, Transactive Memory Systems and Collective Efficacy in Professional Football Teams: A Multilevel Structural Equation Analysis}

Leo, Francisco, González-Ponce, Inmaculada, García-Calvo, Tomás, Sánchez-Oliva, David and Filho, Edson

Available at https://clok.uclan.ac.uk/25740/

Leo, Francisco, González-Ponce, Inmaculada, García-Calvo, Tomás, SánchezOliva, David and Filho, Edson orcid iconORCID: 0000-0002-8548-4651 (2019) The Relationship among Cohesion, Transactive Memory Systems and Collective Efficacy in Professional Football Teams: A Multilevel Structural Equation Analysis. Group Dynamics: Theory, Research, and Practice, 23 (1). pp. 44-56. ISSN 1089-2699

It is advisable to refer to the publisher's version if you intend to cite from the work. http://dx.doi.org/10.1037/gdn0000097

For more information about UCLan's research in this area go to http://www.uclan.ac.uk/researchgroups/ and search for <name of research Group>.

For information about Research generally at UCLan please go to http://www.uclan.ac.uk/research/

All outputs in CLoK are protected by Intellectual Property Rights law, including Copyright law. Copyright, IPR and Moral Rights for the works on this site are retained by the individual authors and/or other copyright owners. Terms and conditions for use of this material are defined in the policies page. 
Running head: COHESION, TRANSACTIVE MEMORY, COLLECTIVE EFFICACY 1

1

19

20

21 22 Lancashire PR1 2HE, UK.

23 E-mail: efilho@uclan.ac.uk

Correspondence:

Dr. Edson Filho

Mauscript Accepted for Publication at Group Dynamics: Theory, Research, and Practice This paper is not the copy of record and may not exactly replicate the final, authoritative version of the article. The final article will be available, upon publication, via its DOI:

$$
\text { 10.1037/gdn0000097 }
$$

\section{The Relationship among Cohesion, Transactive Memory Systems and Collective} Efficacy in Professional Football Teams: A Multilevel Structural Equation Analysis

Francisco M. Leo ${ }^{1}$, Inmaculada González-Ponce², Tomás García-Calvo², David SánchezOliva $^{2,3}$, and Edson Filho ${ }^{*}$

University of Central Lancashire, School of Psychology, Darwin Building, DB114, Preston, 
Running head: COHESION, TRANSACTIVE MEMORY, COLLECTIVE EFFICACY 2

1

2 We explored the interrelationship among cohesion, transactive memory systems (TMS), and

\section{Abstract} collective efficacy in professional football. Specifically, we tested the hypothesis that TMS would mediate the relationship between cohesion and collective efficacy in football teams. Furthermore, we explored the specific effects of task and social cohesion on TMS, under the hypothesis that task cohesion would be a stronger predictor of TMS akin to previous literature on the topic. Five-hundred and fifty-seven footballers (326 male and 231 female) representing 34 different teams competing in the Spanish League First and Second Division "b” participated in the study. Multi-level structural equation modelling analysis revealed that TMS mediated the cohesion-collective efficacy linkage. However, when examining the specific effects of task and social cohesion our analysis suggested that cohesion was exogenous to both TMS and collective efficacy, which in turn correlated with one another (i.e., reciprocal effect relationship). Our findings also revealed that task cohesion had a stronger impact on TMS and collective efficacy than social cohesion. Taken together, these findings suggest that the relationship among cohesion and other team processes may yield equivalent and nonequivalent models of different structural shapes. In practice, these findings highlight the need to develop integrated team dynamics interventions as cohesion influences TMS, which in turn influences collective efficacy and vice-versa. In other words, the higher the "togetherness", the higher information sharing (TMS) and mutual trust in the team.

Keywords: cohesion, transactive memory systems, collective efficacy, football, group dynamics. 
Running head: COHESION, TRANSACTIVE MEMORY, COLLECTIVE EFFICACY 3

\section{The Relationship among Cohesion, Transactive Memory Systems and Collective} Efficacy in Professional Football Teams: A Multilevel Structural Equation Analysis

Various scholars have examined the linkage between cohesion and collective efficacy (Filho, Tenenbaum, \& Yang, 2015; Kozub \& McDonnell, 2000; Paskevich, Brawley, Dorsch, \& Widmeyer, 1999; Spink, 1990), and their relationship with performance in sports (Benson, Šiška, Eys, Priklerová, \& Slepička, 2016; Eys et al., 2015; Fransen et al., 2015). In this regard, there is emerging consensus that higher cohesion leads to higher collective efficacy (Heuzé, Raimbault, \& Fontayne, 2006a; Leo, González-Ponce, Sánchez-Oliva, Amado, \& García-Calvo, 2016b). Nevertheless, only a few studies have examined the input-output (i.e., antecedent; moderating and/or mediating; and outcome variables) mechanism between cohesion and collective efficacy.

Higher cohesion among teammates tends to encourage players to spend more time together, and communicate better and more frequently with each other about aspects of the game, thereby leading to the development of more accurate shared knowledge states within the team (Filho et al., 2015; Kozlowski \& Chao, 2012; Leo, González-Ponce, Amado, Pulido, \& García-Calvo, 2016a). In turn, this shared knowledge held by teammates about "who is aware of what information,” also known as a transactive memory system (Fiore, Salas, \& Cannon-Bowers, 2001, p. 385; Wegner, Erber, \& Raymond, 1991), tends to generate a greater sense of shared efficacy beliefs (Lin \& Chou, 2009). Therefore, the purpose of this study was to examine the role of transactive memory systems on the relationship between cohesion and collective efficacy.

\section{Cohesion}

Cohesion has been defined as "a dynamic process that is reflected in the tendency for a group to stick together and remain united in the pursuit of its instrumental objectives and/or for the satisfaction of member affective needs” (Carron, Brawley, \& Widmeyer, 1998, p. 
Running head: COHESION, TRANSACTIVE MEMORY, COLLECTIVE EFFICACY 4

1 213). This definition, which is congruent with Carron's and associates' model (Carron \& Eys,

2 2012; Carron, Widmeyer, \& Brawley, 1985), reflects the notion that team members hold (a)

3 collective beliefs about the group as a unit in terms of its closeness, resemblance, and affinity

4 (i.e., group integration; GI); and (b) individual beliefs regarding the degree to which the

5 group attracts them, thereby satisfying their needs and personal goals (i.e., individual

6 attraction to the group; ATG). Noteworthy, each of these classes of beliefs is further divided

7 into two categories, depending on whether they revolve around task (T) or social (S) matters

8 (Carron \& Eys, 2012). Altogether, four aspects of team cohesion have been identified: (a)

9 Group Integration-Task (GI-T) and (b) Group Integration-Social (GI-S) which reflect,

10 respectively, members' beliefs about the degree to which the group is united to reach its

11 objectives and to socialize; and (c) Individual Attraction to the Group-Task (ATG-T) and (d)

12 Individual Attraction to the Group-Social (ATG-S) which reflect individual members'

13 attraction to the group for its objectives and social relationships, respectively.

\section{Collective Efficacy}

Collective efficacy pertains to “a group’s shared beliefs in its capacities to organize and execute actions to produce a desired goal” (Bandura, 1997, p. 476). Of note, collective efficacy depends on a series of inputs, including group cohesion (Filho et al., 2015; Heuzé et al., 2006a; Leo et al., 2015a; Paskevich et al., 1999; Short, Sullivan, \& Feltz, 2005; Spink, 1990). According to Bandura (1997), these inputs help to create a shared collective efficacy belief in the team, which in turn has been shown to influence performance outcomes in sports (Beauchamp, 2007; Feltz \& Lirgg, 1998; Leo et al., 2016b). Regarding the relationship between cohesion and collective efficacy, cohesion is considered to be an antecedent of collective efficacy (Bandura, 1997; Kozub \& McDonnell,

24 2000; Leo et al., 2016b). In fact, previous research has shown that team members who 
Running head: COHESION, TRANSACTIVE MEMORY, COLLECTIVE EFFICACY 5

1 perceive greater team cohesion develop stronger perceptions of collective efficacy (Filho et

2 al., 2015; Heuzé et al., 2006a; Leo et al., 2016b).

Previous regression-based studies have revealed that both task and social cohesion are

4 positively related to collective efficacy in team sports (Heuzé et al., 2006a; Kozub \&

5 McDonnell, 2000; Leo et al., 2015a; Leo et al., 2016b; Paskevich et al., 1999; Spink, 1990).

6 However, the magnitude of the relationship between task and social cohesion and colletive

7 efficacy and other team processes depends on competitive level and sport type (Carron,

8 Colman, Wheeler, \& Stevens, 2002). In amateur and youth sports, teammates constitute a

9 fundamental social group for players and, thereby, social cohesion has been found to predict

10 collective efficacy (Filho et al., 2015; Leo et al., 2016b). However, in professional teams, players do not necessarily perceive their teammates as an important social group and, thereby, social cohesion is not necessarily linked to collective efficacy (Kozub \& McDonnell,

2000; Leo et al., 2015a; Paskevich et al., 1999). Furthermore, task cohesion has been found to

be more important in interactive team sports, which require players to continuously

cooperate, than in coactive sports wherein players have fewer opportunities to work together on a team task (Carron et al., 2002; Filho, Dobersek, Gershgoren, Becker, \& Tenenbaum, 2014a). Gender effects have also been found to influence cohesion and collective efficacy, as men's and women's orientation towards cooperation tends to differ (Filho et al., 2014a; Feltz, Short, \& Sullivan, 2008).

Additionally, the relationship between cohesion and collective efficacy might depend on other team processes. Previous studies have examined the influence of task and ego motivational climates on the relationship between cohesion and collective efficacy (Heuzé, Sarrazin, Masiero, Raimbault, \& Thomas, 2006b; Fuster-Parra, García-Mas, Ponseti \& Leo, 2015). However, to our knowledge, only one study has examined the linkage among cohesion, collective efficacy and a team cognitive (i.e., what players know about the team) 
1 construct (Filho et al., 2015). Specifically, Filho et al. (2015) proposed the Integrated

2 Framework of Team Dynamics, linking cohesion and collective efficacy to team mental

3 models and team performance. More specifically, Filho et al. (2015) observed that cohesion

4 was exogenous to both collective efficacy and team mental models, which in turn co-varied

5 and positively influenced team performance. In the present study, we were also interested in

6 the linkage among cohesion, collective efficacy and a team cognition construct similar to the

7 notion of team mental models, namely transactive memory systems.

\section{Transactive Memory Systems}

Transactive memory systems (TMS) is linked to the functioning of working teams across performance domains (Peltokorpi, 2008). Specifically, TMS pertain to “a shared system for encoding, storing, and retrieving information” (Wegner et al., 1991, p. 923), or "the set of knowledge that each individual possesses and the intersubjective awareness of the knowledge that is possessed by others -who knows what-” (Sánchez-Manzanares, Rico, Gil, \& Martín, 2006, p. 751). In practice, TMS can be seen in set-pieces in team sports (such as corner kicks), or when a player produces a "no-look pass" to a teammate, illustrating their shared awareness of the ongoing game situation. TMS develop as team members learn about their fellow teammates’ experiences, preferences, interests, and abilities (Argote \& Guo, 2016). In other words, to maintain the effectiveness of TMS, team members must interact and continually update information about each other’s skills (Brandon \& Hollingshead, 2004).

The construct of TMS is relevant to research on team dynamics because it attempts to examine (a) the knowledge and skills provided by different members of a team; (b) the quantity and quality of knowledge the team as a whole possesses; and (c) how knowledge and skills are distributed within the team. To this extent, previous research has revealed that TMS is manifested in three dimensions: (a) specialization, i.e., the existence in the team of a differentiated structure of knowledge; (b) credibility, i.e., mutual trust among team members 
1 about the validity of their knowledge; and (c) coordination, i.e., the team's capacity to

2 effectively integrate its actions and knowledge (see Gino, Argote, Miron-Spektor, \&

3 Todorova, 2010; Michinov \& Michinov, 2009; Moreland \& Argote, 1998).

Noteworthy, the three reflective indicators of TMS are likely to improve if social

5 cohesion is enhanced in the team, as players that get along well are more likely to share

6 information with one another (Filho, Gershgoren, Basevitch, Schinke, \& Tenenbaum, 2014c).

7 Generally, the most effective teams are those whose members feel connected to one another,

8 as such connectedness allows them to share their expertise (Argote \& Ren, 2012). High

9 integration among team members leads to closer interpersonal relations, thus favoring the emergence of shared understanding and coordination within the team (Bourbousson, Poizat,

11 Saury, \& Seve, 2010). Besides social interaction, TMS will also be enhanced with training, particularly when team members learn how to perform a given task cooperatively (Argote \&

Ren, 2012). Moreover, the existence of well-defined roles in the team promotes shared understanding and coordination amongst team members performing an interdependent task (Bosselut, McLaren, Eys, \& Heuzé, 2012; Giske, Rodahl, \& Høigaard, 2015). Therefore, group cohesion is expected to antecede the development of TMS in sport teams. Teammates need to develop task-related and social bonds in order "to come and stick together" (i.e., cohesion), so that they can develop an understading of "who knows what" (TMS) in order to coordinate their actions in the natural world (Bourbousson et al., 2010; Leo et al., 2016a; Williamson \& Cox, 2014). Teams with players who feel more integrated and attracted by the group may not only develop greater TMS but also evolve higher levels of collective efficacy. In fact, Liang, Moreland, and Argote (1995) argued that TMS is positively related to the collective level of confidence shared among players, given that when group members have extensive shared 25 knowledge about the team, developing trust in the team is a natural process. As alluded to 
Running head: COHESION, TRANSACTIVE MEMORY, COLLECTIVE EFFICACY 8

1 previously, research on team sports has also shown that cohesion predicts team mental

2 models (Filho et al., 2015), which is similar to the notion of TMS (Fiore et al., 2001).

3 Research with hand-to-hand circus acrobats has identified that shared knowledge among

4 teammates and collective efficacy are intertwined team processes (Filho \& Rettig, in press).

5 In the present study we were interested in examining the relationship among cohesion, TMS,

6 and collective efficacy.

\section{Aims and Hypotheses}

We aimed to examine the interrelationship among cohesion, TMS, and collective

9 efficacy through multilevel structural equation modelling. First, we aimed to test a model, as

10 informed by previous empirical and theoretical work (see Filho et al., 2015; Heuzé et al.,

11 2006a; Leo et al., 2016a), reflecting the notion that overall cohesion scores are related to

12 TMS and collective efficacy. In particular, we hypothesized that cohesion is an antecedent of

13 TMS, which in turn mediates the relationship between cohesion and collective efficacy in

14 professional football teams (H1). Furthermore, we also tested the specific effects of task and

15 social cohesion on TMS, while accouting for the influence of TMS on collective efficacy.

16 Specifically, we predicted that task cohesion would be a stronger predictor of TMS (H2).

\section{Method}

\section{Participants}

Five-hundred and fifty-seven professional football players competing in the Spanish Soccer League participate in the study. All soccer clubs that were members of the men's Second Division “b” (20 teams) and the women's First Division (16 teams) were invited to take part in the study. A total of 18 teams competing in the Second Division "b" and 14 teams competing in the First Division agreed to take part in the study. Three-hundred and twentysix male athletes, ranging in age from 16 to 37 years $(M=25.31, S D=4.58)$, and 231 female footballers, ranging in age from 15 to 36 years $(M=22.37, S D=4.49)$, took part in the study. 
Running head: COHESION, TRANSACTIVE MEMORY, COLLECTIVE EFFICACY 9

\section{Instruments}

Cohesion. The short Spanish version of the GEQ (Leo et al., 2015b) was used to assess cohesion. This scale has 12 items comprising four factors with three items each, namely group integration-social (GI-S; e.g., “The members of our team like to get together in situations other than trainings and matches”), group integration-task (GI-T; e.g., "The team members unite their efforts to achieve the goals during trainings and matches”), individual attraction to the group-social (ATG-S; e.g., "If there is any problem during the training sessions, all the players get together to overcome it”), and individual attraction to the grouptask (ATG-T; e.g., "I like the way this team plays”). Players responded to all items on a ninepoint scale ranging from strongly disagree (1) to strongly agree (9). The CFA showed acceptable model fit $\left(\chi^{2}=149.505 ; \mathrm{df}=48 ; p \leq .001\right.$; CFI $=.957$; TLI $=.941$; RMSEA $=$ .062 ; SRMR $=.041)$. Furthermore, Cronbach's alpha coefficients were acceptable, with values of .85 for GI-S, .86 for GI-T, .83 for ATG-S, .78 for ATG-T, and .89 for the full scale. Transactive memory systems. To assess TMS, we used a questionnaire developed by Lewis (2003), and adapted to the sport contex by Leo, González-Ponce, Sanchez-Oliva, Pulido, and García-Calvo (2018). The questionnaire consists of 15 items organized in three factors: specialization (five items, e.g., "Different team members are responsible for expertise in different areas”), credibility (five items, e.g., "I was comfortable accepting procedural suggestions from other team members”), and coordination (five items, e.g., “Our team had very few misunderstandings about what to do”). Players responded to all items on a fivepoint scale ranging from strongly disagree (1) to strongly agree (5). The H-CFA showed acceptable model fit $\left(\chi^{2}=209.537 ; \mathrm{df}=63 ; p \leq .001\right.$; CFI $=.947 ; \mathrm{TLI}=.912 ; \mathrm{RMSEA}=$ .065 ; SRMR $=.028)$. Furthermore, Cronbach's alpha coefficients were acceptable, with values of .77 for specialization, .85 for credibility, .79 for coordination, and .81 for the full scale. 
1 Collective efficacy. To assess collective efficacy, we used the Football Collective

2 Efficacy Questionnaire developed by Leo et al. (2014). This instrument starts with a stem

3 phrase (i.e., “Our team’s confidence in our capability to...”) and has a total of six items

4 referring to specific football situations (e.g., “...resolve game situations in the attacking

5 phase"), which are all grouped into a single factor. The questionnaire uses a five-point likert

6 scale ranging from bad (1) to excellent (5). The CFA showed acceptable model fit $\left(\chi^{2}=\right.$

$7 \quad 29.961 ; \mathrm{df}=9 ; p \leq .001 ; \mathrm{CFI}=.972 ; \mathrm{TLI}=.954 ; \mathrm{RMSEA}=.065 ; \mathrm{SRMR}=.029)$. The

8 Cronbach's alpha coefficient was acceptable for the full scale, $\alpha=.81$.

\section{Procedure}

Institutional ethical approval was secured prior to the commencement of data

collection. All participants were treated according to the American Psychological Association ethical guidelines regarding consent, confidentiality, and anonymity of responses. To arrange data collection meetings, we contacted the clubs and coaches of all teams participating in the women’s First Division and the men’s Second Division “b” Spanish football leagues, respectively. Noteworthy,a cross-sectional design was used and a single data collection assessment was completed during the middle of the season to ensure the teams had developed a sense of cohesion, collective efficacy and TMS. Coaches and team representatives were briefed on the objectives and procedures of the study. Dates and times for data collection were arranged with those teams willing to take part in the study. At data collection, the players were informed about the research aims and methods, and ensured that participation was voluntary and that their answers would remain confidential. Participants completed questionnaires in the locker room, and without the presence of the coach. The process took approximately 30 minutes. The principal investigator was present at the time the players completed questionnaires, and answered all questions posed by the participants. 
Running head: COHESION, TRANSACTIVE MEMORY, COLLECTIVE EFFICACY 11

\section{Data Analysis}

With respect to the main analysis, we initially examined the measurement model to assess the relationships between the observed indicators and their respective latent constructs.

4 Factor scores from the subscales were used as indicators for the latent factor cohesion, TMS

5 and collective efficacy. Subsequently, we used Multilevel Structural Equation Modelling

6 (MSEM) to test the hypothesized and relevant alternative models. Of note, robust maximum

7 likelihood (MLR) was used as this estimation method procedure is robust to the Likert nature

8 of the questionnaire items and non-normal data distribution (Muthén \& Muthén, 1998-2018).

To assess the models' fit, we used the following indices: chi-square $\left(\chi^{2}\right)$, comparative

10 fit index (CFI), Tucker Lewis index (TLI), root mean square error of approximation

11 (RMSEA), and standardized root mean square residual (SRMR). According to Schumacker and Lomax (1996), incremental indexes (CFI and TLI) indicate acceptable fit when values of .90 or higher are obtained. Regarding RMSEA and SRMR, .08 or .06 have been established as acceptable cut-off points (Hu \& Bentler, 1999).

\section{Results}

\section{Descriptive Statistics, Correlations and Cronbach’s Alpha Coefficients}

Means, standard deviations, correlations and Cronbach’s alpha coefficients for each

variable are presented in Table 1 . Scales demonstrated acceptable internal consistency (i.e., $\alpha$

$>$.70). Regarding the mean values, in general, the participants reported scores above the

midpoint of the scale for cohesion, TMS and collective efficacy.

\section{Multilevel Structural Equation Modelling}

Intraclass correlation indicates the total amount of variance in a given variable of interest that is due to group-level effects. In this study, coefficients for each subscales were

24 all above .14 (range $=.14-.27$; see Table 1 ), indicating the need for multilevel analysis. To

25 this extent, multilevel structural equation modelling should start with the model labelled as 
1 maximal model, which consists of two levels (i.e. between and within levels; see Stapleton,

2 2006). This model is meant to decompose the observed covariance matrix into two components: (a) the covariance matrix for the between level, and (b) the covariance matrix

4 for the within level. First, we tested the multilevel model with random intercepts and random

5 slopes. The maximal model did not converge to a solution. Then, we tested the multilevel

6 model with random intercepts and fixed slopes, and again the model did not converge to a

7 solution. This is likely due to the small sample size for the between level (i.e., 31 teams) and

8 the homogeneity of the sampled teams (i.e., all teams participated in two professional

9 leagues). Specifically, when the simple size for the between level is small $(<100)$ and

10 homogenous, the model tends to encounter convergence problems as the variance for the

11 between-level parameters tends to be small (Maas \& Hox, 2005). Due to the previous results, we tested another model targeting the individual level of analysis, and the information about the nesting of individuals within teams was incorporated via correction of standard errors of the parameters, using the Mplus COMPLEX instruction (Muthén \& Muthén, 1998-2018). This procedure allowed us to control for the nesting of players within teams.

Hypothesized model 1. Initially, we used a two-step model-building (Anderson \&

17 Gerbing, 1988) to test the proposed model (Figure 1). Confirmatory factor analysis was carried out to test the measurement model in step 1 . The fit indices indicated that the measurement model adequately described the data $\left(\chi^{2}=458.736\right.$; $\mathrm{df}=182 ; p \leq .001$; CFI $=$ $.941 ; \mathrm{TLI}=.932 ; \mathrm{RMSEA}=.052 ; \mathrm{SRMR}=.053$ ) with acceptable factor loadings (from .57 to .91). In the second step we used MSEM to analyse the relationship among cohesion, TMS, and collective efficacy. We included cohesion as an independent variable, TMS as a mediator, and collective efficacy as an outcome variable (Figure 1). Results of the SEM analysis revealed that the hypothesized model 1 represented a good fit to the data $\left(\chi^{2}=\right.$ 460.085; $\mathrm{df}=183 ; p \leq .001 ; \mathrm{CFI}=.941 ; \mathrm{TLI}=.932 ; \mathrm{RMSEA}=.052 ; \mathrm{SRMR}=.053)$. Figure 
11 shows the standardized results of the model, which revealed that (a) cohesion was a strong

2 positive predictor of TMS $\left(\beta=.858, p<.001, R^{2}=.736\right)$, and (b) TMS predicted collective

3 efficacy $\left(\beta=.771, p<.001, R^{2}=.594\right)$.

To ensure that the hypothesized model provided the best fit indices, one meaningful alternative model was tested (Hershberger, 2006). We replaced the direct effect from TMS to collective efficacy with the correlation between their disturbances. Accordingly, TMS and collective efficacy hypothesised were as sharing covariance rather than representing a linear process. This model was tested because there is previous empirical evidence suggesting that cohesion predicts collective efficacy in team sports (Filho et al., 2015; Heuzé et al., 2006a; Kozub \& McDonnell, 2000; Leo et al., 2015a; Leo et al., 2016b). Results showed that cohesion was a strong positive predictor of TMS $\left(\beta=.863, p<.001, R^{2}=.745\right)$ and collective efficacy $\left(\beta=.650, p<.001, R^{2}=.423\right)$, and the alternative model had acceptable fit of the data $\left(\chi^{2}=458.738 ; \mathrm{df}=182 ; p \leq .001 ; \mathrm{CFI}=.941 ; \mathrm{TLI}=.932 ; \mathrm{RMSEA}=.052\right.$; SRMR $=.053)$. Thus, the final step consisted of conducting a $\chi^{2}$ difference test $(\Delta \chi 2)$ to determine whether the hypothesized model fit the data significantly better than the alternative model. A non-significant effect was observed $\left(\Delta \chi^{2}(1)=1.208, p=.272\right)$, suggesting that the alternative model did not fit significantly better than the hypothesized model 1 . In other words, the hypothesized model was not better than the alterntive model.

Hypothesized model 2. To test whether cohesion factors predicted TMS, we tested a model with the four cohesion factors as antecedents of TMS and collective efficacy as the outcome variable (Figure 2). The hypothesized model 2 showed an adequate fit to the data $(\chi$ $\left.{ }^{2}=400.390 ; \mathrm{df}=178 ; p \leq .001 ; \mathrm{CFI}=.952 ; \mathrm{TLI}=.944 ; \mathrm{RMSEA}=.047 ; \mathrm{SRMR}=.043\right) . \mathrm{A}$ $\chi 2$ difference test revealed that this model fit the data better than the hypothesized model 1 , $\Delta \chi^{2}(1)=58.348, p<.001$. In particular, model 2 revealed that only task cohesion factors, GI$\mathrm{T}(\beta=.650, p<.001)$ and ATG-T $(\beta=.271, p<.001)$, predicted TMS $\left(R^{2}=.744\right)$. 
1 Furthermore, TMS was found to predict collective efficacy $\left(\beta=.772, p<.001 ; R^{2}=.596\right)$.

2 Finally, our analysis revealed a somewhat unexpected effect insofar that GI-S was found to

3 negatively predict TMS, albeit the observed effect was low $(\beta=-.136, p<.01)$. We reasoned

4 that social cohesion at the team-level of analysis (GI-S) can be related to "groupthink" and

5 we expand on the implications of this unexpected finding in the discussion section.

6 Alternative model 2. We ran an alternative model with the same paths of the

7 hypothesized model, except that we replaced the direct effect from TMS to collective

8 efficacy with a correlation between these variables. Results showed that task cohesion (GI-T

9 and ATG-T, $\beta=.258-.674, p<.001)$ predicted TMS $\left(R^{2}=.749\right)$ and collective efficacy $\left(R^{2}\right.$

$10=.429)$. This alternative model 2 had an acceptable fit of the data as the hypothesized model

$2\left(\chi^{2}=408.062 ; \mathrm{df}=176 ; p \leq .001 ; \mathrm{CFI}=.950 ; \mathrm{TLI}=.941 ; \mathrm{RMSEA}=.049 ; \mathrm{SRMR}=.045\right)$.

A $\chi^{2}$ difference $\left(\Delta \chi^{2}\right)$ test revealed that this alternative model represented a significantly

better fit to the data than the hypothesized model 2, $\Delta \chi^{2}(1)=7.864, p<.01$ ).

\section{Invariance test}

Invariance analysis was conducted (see Bentler, 1995) to examine whether the final

alternative model 2 was equivalent across gender. First, the measurement models by gender

were estimated and showed appropriate fit for both genders. For the male group, $\chi^{2}=$

336.568; $\mathrm{df}=174 ; p \leq .001 ; \mathrm{CFI}=.936 ; \mathrm{TLI}=.923 ; \mathrm{RMSEA}=.054 ; \mathrm{SRMR}=.045$. For the

female group, $\chi^{2}=347.249 ; \mathrm{df}=174 ; p \leq .001 ; \mathrm{CFI}=.919 ; \mathrm{TLI}=.903$; $\mathrm{RMSEA}=.056$;

SRMR $=.064$. Second, the invariance model, in which the hypothesized model is fitted for

both genders concurrently, did not converge. Noteworthy, the fact that the measurement

models for both groups showed acceptable fit suggests that the latent variables under analysis have the same meaning for both males and females (Schmitt \& Kuljanin, 2008). The fact that 
1 variables (Alternative Model 2) for males and females does not differ significantly

2 (Hershberger, 2006).

\section{Discussion}

The purpose of this study was to examine the interrelationship among cohesion, TMS, and collective efficacy in professional football. We hypothesized (H1) that TMS would mediate the relationship between cohesion and collective efficacy in professional football teams. Our results did not support $\mathrm{H} 1$ but rather revealed that a non-mediation model, in which collective efficacy and TMS co-vary, is better than the originally proposed model in which TMS mediated the relationship between cohesion and collective efficacy. Together, the final model suggests that cohesion leads to TMS, and that TMS and collective efficacy share a reciprocal effect rather than a causal relationship. Moreover, correlational analysis revealed that cohesion, TMS, and collective efficacy were positively correlated. These findings are in line with previous evidence in sport psychology on the positive relationship among cohesion, shared knowledge states (e.g., TMS and team mental models), and collective efficacy (Filho et al., 2015; Heuzé et al., 2006a; Leo et al., 2015a; Leo et al., 2016a). In practice, these findings highlight the importance of systemic applied interventions that enhance "coming and staying together” (i.e., cohesion), sharing of information within the team (i.e., TMS), and trusting one another and "the team as a whole" (i.e., collective efficacy). In other words, cohesive teammates are more likely to share information with and have confidence in one another.

We also tested the specific effects of task and social cohesion on TMS. To this end, we hypothesized (H2) that task cohesion would be a stronger predictor of TMS than social cohesion. Our analysis revealed that task cohesion at both the individual and group level of analysis was a stronger predictor of TMS than social cohesion. These findings are congruent with previous research showing that task cohesion is oftentimes more important to team 
1 functioning and performance than social cohesion (see Carron et al., 2002). To this extent,

2 Carron and Brawley (2000) have long noted that "Cohesion has an instrumental basis. All

3 groups - musical groups, work groups, sport groups, committee, form for a purpose. Even

4 groups that may be considered purely 'social' in nature have an instrumental basis for their

5 formation” (p. 95). Noteworthy, the fact that task cohesion was found to be a stronger

6 predictor of TMS in the present study might also reflect our sample of professional sport

7 teams, which by definition "come and remain united” (cohesion) to perform a task. Social

8 cohesion might be more important in less competitive environments, or when task cohesion is

9 similar across competitive teams (Filho, Gershgoren, Basevitch, \& Tenenbaum, 2014b).

Our analysis also revealed that perceived cohesion at the team level of analysis (GI-T)

was a stronger predictor of TMS than task cohesion at the individual level of analysis (ATG-

T). Therefore, group-level effects (“we beliefs”) might be more important to team

functioning than individual-level effects ("I beliefs"), thereby highlighting the importance of multi-level analytical approaches in the study of nested data sets (Muthén \& Muthén, 19982018). In fact, team processes, such as cohesion and TMS, are emergent states insofar that they arise from "the team as a whole" rather than from any single team member (Grossman, Friedman, \& Kalra, 2017). In practice, our findings suggest that the overall "we perception of cohesion” within a team is more important in triggering the development of TMS than individual players' feeling about their bonds to the team.

It is also important to note that social cohesion at the team level of analysis (GI-S) was found to be weakly yet negatively related to TMS. These apparently contradictory findings resonate with the well-established notion of "groupthink" (see De Wit, Greer, \& Jehn, 2012). High levels of social cohesion can prevent individuals from searching for better action plans, sharing knowledge, and disputing non-optimal decision-making in team settings. In fact, this so called "too much of good thing effect” for team processes has been 
1 observed before and illustrates the complexity and non-linearity of team dynamics in sports

2 and beyond (Pierce \& Aguinis, 2013). Put plainly, high levels of social cohesion might be

3 functional for some teams and performance contexts but counter-productive for other teams

4 and contexts. For instance, professional sport teams, which were the sampled population in

5 this study, focus primarily on the task and thus might be less susceptible to compromising

6 task performance at the expense of social cohesion. On the other hand, groupthink might be

7 more likely to occur in teams primarily united by the social need to belong (e.g., recreational

8 sport teams). Longitudinal studies are promising avenues of future research to explore

9 whether the relationship between social cohesion with other team processes is indeed non-

10 linear and moderated by other factors such as performance level and sport type (e.g., coactive 11 and interactive).

In the present study, we abided by current guidelines on structural equation modelling and tested for alternative models. When considering the aggregated scores for cohesion (H1), our analysis revealed that the hypothesized model wherein TMS mediated the relationship between cohesion and collective efficacy was not superior to an alternative model wherein cohesion was exogenous to TMS and collective efficacy, which in turn were found to share a recirprocal effects relationship (Figure 1). When testing the specific effects of cohesion (H2), our analysis suggested that TMS does not mediate the relationship between cohesion and collective efficacy. Rather, social and task cohesion were found to antecede TMS and collective efficacy, which in turn were found to co-vary (Figure 2). Together, these findings corroborate the notion that cognitive team processes (e.g., TMS, team mental models) and collective efficacy share a reciprocal effect rather than a causal relationship (Filho et al., 2015).

Methodologically, this pattern of findings suggests that the analysis of aggregated and non-aggregated data may lead to different conclusions in the study of input-output relations. 
1 Theoretically, these findings corroborate previous input-output models proposed in the

2 literature (Carron \& Eys, 2012; Filho et al., 2015), insofar that the relationship between

3 cohesion and other team processes may yield alternative (equivalent and non-equivalent)

4 models. Above all, the relationship among team processes is dynamic rather than "one-size

5 fits all”, and thus practitioners must develop systemic interventions tailored to the specific

6 needs of a given team and aimed at concomitantly addressing cohesion, TMS, and collective

7 efficacy beliefs. In particular, the relationship among team processes hinges on individual,

8 team, and contextual factors (Grossman et al., 2017). For a given team (made up of a set of

9 individuals) in a given performance context, cohesion might lead to the development of TMS,

10 whereas in other circumstances cohesion and TMS might co-vary. Similarly to how chemical

11 molecules bind differently to one another depending on a set of circumstances (e.g., temperature, pressure) team processes might relate differently to one another given different circumstances; indeed, that is likely why practitioners speak of "team chemistry" when

14 discussing the relationship among various team processes (see Filho, 2015).

15 Limitations \& Future Research

First, our study is cross-sectional and cause-and-effect relationships as well as time bounded effects cannot be established. Experimental work, comparing established and newly formed teams, might illuminate the means-to-end relationships (i.e., what comes first) among cohesion, TMS, and collective efficacy. In this regard, future research is also needed to differentiate theoretically proximal concepts such as shared mental models, TMS, and team coordination. Longitudinal studies might reveal how and why the relationship among team processes fluctuates (increases or decreases) due to performance and other factors (e.g., home field advantage; low- and high-pressure contexts). 
1 recreational, college, professional) is important, as the linkage among different team

2 processes (e.g., cohesion, TMS, collective efficacy) might differ due to performance pressure.

3 It is also worth exploring whether the relationship among team processes (e.g., cohesion,

4 TMS, and collective efficacy) vary due to individual (e.g., role within the team), team (e.g.,

5 size of the team), and contextual factors (e.g., cultural effects). To this extent, individual

6 factors, team factors, and contextual factors are thought to interact and together influence

7 team dynamics (Grossman et al., 2017). For instance, playmakers (i.e., players in centralized

8 positions) perceive team performance differently than others (Filho et al., 2014b), and there is

9 also evidence that team size, as well as cultural background and nationality, influences team

10 dynamics in sports (for a review see Carron \& Eys, 2012). Finally, comparing high and low

11 performing teams (i.e., the expert novice paradigm) is paramount to identify the mechanisms underpinning optimal performance in team settings, and consequently to advance evidencebased guidelines to develop high-performing teams

\section{Conclusion \& Applied Implications}

To conclude, we reinforce the importance of systemic interventions addressing the linkage between cohesion, TMS, and collective efficacy. Notwithstanding, although the overall pattern of correlation among cohesion, TMS and collective efficacy was positive, when we analyzed the inter-relationships among these constructs via structural equation modelling our results revealed that GI-S was a negative predictor of TMS. Thus, practitioners must be aware of the "too much of a good thing effect" for social cohesion, and recognize that at times excessive "togetherness" might lead to "groupthink" and preclude rather than propel optimal team functioning in professional football. This aside, enhancing cohesiveness will positively influence the development of shared knowledge states which in turn influence

24 the development of collective efficacy, and vice-versa. Noteworthy, specific recommendations to enhance cohesion, team knowledge and efficacy beliefs are available in 
Running head: COHESION, TRANSACTIVE MEMORY, COLLECTIVE EFFICACY 20

1 the literature (see Argote \& Guo, 2016; Carron \& Eys, 2012; Short et al., 2005), and we thus

2 invite practitioners to study the so called "reflective indicators" of various team processes

3 (e.g., social and task cohesion; specialization and creditability for TMS; preparation and skill

4 mastery for collective efficacy) in order to be able to propose integrated interventions that

5 unite team members, while facilitating the sharing of information and development of mutual

6 confidence within sport teams.

7 
Running head: COHESION, TRANSACTIVE MEMORY, COLLECTIVE EFFICACY 21

References

Argote, L., \& Guo, J. M. (2016). Routines and transactive memory systems: Creating, coordinating, retaining, and transferring knowledge in organizations. Research in Organizational Behavior, 36, 65-84. doi:10.1016/j.riob.2016.10.002

Argote, L., \& Ren, Y. (2012). Transactive memory systems: A microfoundation of dynamic capabilities. Journal of Management Studies, 49, 1375-1382. doi:10.1111/j.14676486.2012.01077.x

Bandura, A. (1997). Self-efficacy: The exercise of control. New York: Freeman.

Beauchamp, M. R. (2007). Efficacy beliefs within relational and group contexts in sport. In S. Jowett \& D. Lavallee (Eds.), Social psychology in sport (pp. 181-193). Champaign: Human Kinetics Publishers.

Benson, A. J., Šiška, P., Eys, M., Priklerová, S., \& Slepička, P. (2016). A prospective multilevel examination of the relationship between cohesion and team performance in elite youth sport. Psychology of Sport and Exercise, 27, 39-46. doi: 10.1016/j.psychsport.2016.07.009

Bentler (1995)

Bosselut, G., McLaren, C. D., Eys, M. A., \& Heuzé, J. P. (2012). Reciprocity of the relationship between role ambiguity and group cohesion in youth interdependent sport. Psychology of Sport and Exercise, 13, 341-348. doi:10.1016/j.psychsport.2011.09.002

Bourbousson, J., Poizat, G., Saury, J., \& Seve, C. (2010). Team coordination in basketball: Description of the cognitive connections among teammates. Journal of Applied Sport Psychology, 22, 150-166. doi:10.1080/10413201003664657

Brandon, D. P., \& Hollingshead, A. B. (2004). Transactive memory systems in organizations: Matching tasks, expertise, and people. Organization Science, 15, 633-644. doi:10.1287/orsc.1040.0069 
Running head: COHESION, TRANSACTIVE MEMORY, COLLECTIVE EFFICACY 22

1 Carron, A. V., \& Brawley, L. R. (2000). Cohesion: Conceptual and measurement issues. Small Group Research, 31, 89-106. doi:10.1177/104649640003100105

3 Carron, A. V., Brawley, L. R., \& Widmeyer, W. N. (1998). The measurement of cohesiveness in sport groups. Advances in Sport and Exercise Psychology Measurement, 23, 213-226.

Carron, A. V., Colman, M. M., Wheeler, J., \& Stevens, D. (2002). Cohesion and performance in sport: A meta analysis. Journal of Sport \& Exercise Pshycology, 24, 168-188.

Carron, A. V., \& Eys, M. A. (2012). Group dynamics in sport. (4th ed.). Morgantown, WV: itness Information Technology.

Carron, A., Widmeyer, W. N., \& Brawley, L. (1985). The development of an instrument to assess cohesion in sport teams: The Group Environment Questionnaire. Journal of Sport Psychology, 7, 244-266. doi:10.1123/jsp.7.3.244

De Wit, F. R. C., Greer, L. L., \& Jehn, K. A. (2012). The paradox of intragroup conflict: A meta-analysis. Journal of Applied Psychology, 97, 360-390. doi:10.1037/a0024844

Eys, M. A., Evans, M. B., Martin, L. J., Ohlert, J., Wolf, S. A., Van Bussel, M., \& Steins, C. (2015). Cohesion and performance for female and male sport teams. The Sport Psychologist, 29, 97-109. doi:10.1123/tsp.2014-0027

Feltz, D. L., \& Lirgg, C. D. (1998). Perceived team and player efficacy in hockey. Journal of Applied Psychology, 83, 557-564.

Feltz, D. L., Short, S. E., \& Sullivan, P. J. (2008). Self-efficacy in sport. Human Kinetics. Filho, E. (2015). “Team chemistry” through chemistry lenses: interdisciplinary science or a metaphorical conundrum? Frontiers in Psychology, 1-3.

Filho, E., Dobersek, U., Gershgoren, L., Becker, B., \& Tenenbaum, G. (2014a). The cohesion-performance relationship in sport: A 10-year retrospective meta-analysis. Sport Sciences for Health, 10, 165-177. doi:10.1007/s11332-014-0188-7 
Running head: COHESION, TRANSACTIVE MEMORY, COLLECTIVE EFFICACY 23

1 Filho, E., Gershgoren, L., Basevitch, I., \& Tenenbaum, G. (2014b). Profile of highperforming college soccer teams: An exploratory multi-level analysis. Psychology of Sport and Exercise, 15, 559-568.

Filho, E., Gershgoren, L., Basevitch, I., Schinke, R., \& Tenenbaum, G. (2014c). Peer leadership and shared mental models in a college volleyball team: A season long case study. Journal of Clinical Sport Psychology, 8, 184-203.

Filho, E., \& Rettig, J. (In press). Team coordination in high-risk circus acrobatics. Interaction Studies.

Filho, E., Tenenbaum, G., \& Yang, Y. (2015). Cohesion, team mental models, and collective efficacy: Towards an integrated framework of team dynamics in sport. Journal of Sports Sciences, 33, 641-653. doi: 10.1080/02640414.2014.957714

Fiore, S. M., Salas, E., \& Cannon-Bowers, J. A. (2001). Attitudes, behaviors, and cognition in distributed teams: The effect of team opacity on process and performance. In Proceedings of the 4th Annual Meeting of the Human Factors and Ergonomic Society (pp. 382-386). Santa Monica, CA: HFES.

Fransen, K., Decroos, S., Vanbeselaere, N., Broek, G. Vande, Cuyper, B. De, Vanroy, J., ... Vande, G. (2015). Is team confidence the key to success? The reciprocal relation between collective efficacy, team outcome confidence, and perceptions of team performance during soccer games. Journal of Sports Sciences, 33, 219-231. doi:10.1080/02640414.2014.942689

Fuster-Parra, P., García-Mas, A., Ponseti, F. J., \& Leo, F. M. (2015). Team performance and collective efficacy in the dynamic psychology of competitive team: A Bayesian network analysis. Human Movement Science, 40, 98-118. doi:10.1016/j.humov.2014.12.005

Gino, F., Argote, L., Miron-Spektor, E., \& Todorova, G. (2010). First, get your feet wet: The effects of learning from direct and indirect experience on team creativity. 
Running head: COHESION, TRANSACTIVE MEMORY, COLLECTIVE EFFICACY 24

Organizational Behavior and Human Decision Processes, 111, 102-115. doi:10.1016/j.obhdp.2009.11.002

Giske, R., Rodahl, S. E., \& Høigaard, R. (2015). Shared mental task models in elite ice hockey and handball teams: Does it exist and how does the coach intervene to make an impact? Journal of Applied Sport Psychology, 27, 20-34. doi:10.1080/10413200.2014.940431

Grossman, R., Friedman, S. B., \& Kalra, S. (2017). Teamwork processes and emergent states. In E. Salas, R. Rico, \& J. Passmore (Eds.), The psychology of team working and collaborative processes. Hoboken, NJ: Wiley Blackwell.

Hershberger, S. L. (2006). The problem of equivalent structural models. In G. R. Hancock \& R. O. Mueller (Eds.), Structural equation modeling: A second course (pp. 13-41). Charlotte, NC: Information Age Publishing.

Heuzé, J. P., Raimbault, N., \& Fontayne, P. (2006a). Relationships between cohesion, collective efficacy and performance in professional basketball teams: An examination of mediating effects. Journal of Sports Sciences, 24, 59-68. doi:10.1080/02640410500127736

Heuzé, J. P., Sarrazin, P., Masiero, M., Raimbault, N., \& Thomas, J. P. (2006b). The relationships of perceived motivational climate to cohesion and collective efficacy in elite female teams. Journal of Applied Sport Psychology, 18(3), 201-218. doi:10.1080/10413200600830273

Hu, L., \& Bentler, P. M. (1999). Cutoff criteria for fit indexes in covariance structure analysis: Conventional criteria versus new alternatives. Structural Equation Modeling: A Multidisciplinary Journal, 6, 1-55. doi:10.1080/10705519909540118

Kozlowski, S. W. J., \& Chao, G. T. (2012). The dynamics of emergence: Cognition and cohesion in work teams. Managerial and Decision Economics, 33, 335-354. 
Running head: COHESION, TRANSACTIVE MEMORY, COLLECTIVE EFFICACY 25

1

doi:10.1002/mde.2552

Kozub, S. A., \& McDonnell, J. F. (2000). Exploring the relationship between cohesion and collective efficacy in rugby teams. Journal of Sport Behavior, 23(2), 120-129.

Leo, F. M., González-Ponce, I., Amado, D., Pulido, J. J., \& García-Calvo, T. (2016a). An approach to group processes in female professional sport. European Journal of Human Movement, 36, 57-74.

Leo, F. M., González-Ponce, I., Sánchez-Miguel, P. A., Ivarsson, A., \& García-Calvo, T. (2015a). Role ambiguity, role conflict, team conflict, cohesion and collective efficacy in sport teams: A multilevel analysis. Psychology of Sport and Exercise, 20, 60-66. doi: 10.1016/j.psychsport.2015.04.009

Leo, F. M., González-Ponce, I., Sánchez-Oliva, D., Amado, D., \& García-Calvo, T. (2016b). Exploring direction between cohesion and collective efficacy and relationships with performance of football teams. South African Journal for Research in Sport, Physical Education and Recreation, 38(3), 103-116.

Leo, F. M., González-Ponce, I., Sanchez-Oliva, D., Pulido, J. J., \& García-Calvo, T. (2018). Adaptation and validation of the Transactive Memory System Scale in Sport (TMSS-S). International Journal of Sports Science and Coaching, 14, 1-8. doi:10.1177/1747954118767509

Leo, F. M., González-Ponce, I., Sánchez-Oliva, D., Pulido, J. J., \& García-Calvo, T. (2015b). Adaptation and validation in Spanish of the Group Environment Questionnaire (GEQ) with professional football players. Psicothema, 27, 261-268. doi:10.7334/psicothema2014.247

Leo, F. M., Sánchez-Miguel, P. A., Sánchez-Oliva, D., Amado, D., \& García-Calvo, T. (2014). Analysis of the group process and the performance in semiprofessional soccer. Revista Internacional de Medicina y Ciencias de la Actividad Física y el Deporte, 14, 
Running head: COHESION, TRANSACTIVE MEMORY, COLLECTIVE EFFICACY 26

1

2

3

4

5

6

7

8 153-168.

Lewis, K. (2003). Measuring transactive memory systems in the field: Scale development and validation. Journal of Applied Psychology, 88, 587-604. doi:10.1037/00219010.88.4.587

Liang, D. W., Moreland, R., \& Argote, L. (1995). Group versus individual training and group performance: The mediating role of transactive memory. Personality and Social Psychology Bulletin, 21, 384-393. doi:10.1177/0146167295214009.

Lin, Y. H., \& Chou, H. W. (2009). Exploring the formation of collective efficacy in college student learning teams. In Proceedings of World Conference on E-Learning in Corporate, Government, Healthcare, and Higher Education 2009 (pp. 2863-2870). Chesapeake,VA: Association for the Advancement of Computing in Education (AACE).

Maas, C. J. M., \& Hox, J. J. (2005). Sufficient sample sizes for multilevel modeling. European Journal of Research Methods for the Behavioral and Social Sciences, 1, 8692. doi:10.1027/1614-1881.1.3.86

Michinov, N., \& Michinov, E. (2009). Investigating the relationship between transactive memory and performance in collaborative learning. Learning and Instruction, 19(1), 4354. doi:10.1016/j.learninstruc.2008.01.003

Moreland, R. L., \& Argote, L. (1998). Training people to work in groups. In R. S. Tindale, L. Heath, J. Edwards, E. J. Posavac, F. B. Bryant, Y. Suarez-Balcazar, \& E. HendersonKing (Eds.), Theory and research on small groups (pp. 37-60). New York: Plenum.

Muthén, L. K., \& Muthén, B. O. (n.d.). Mplus user's guide (7th ed.). Los Angeles, CA: Muthén \& Muthén.

Paskevich, D. M., Brawley, L. R., Dorsch, K. D., \& Widmeyer, W. N. (1999). Relationship between collective efficacy and team cohesion: Conceptual and measurement issues. Group Dynamics: Theory, Research, and Practice, 3, 210-222. 
Running head: COHESION, TRANSACTIVE MEMORY, COLLECTIVE EFFICACY 27

1 Peltokorpi, V. (2008). Transactive memory systems. Review of General Psychology, 12, 378394. doi:10.1037/1089-2680.12.4.378

3 Pierce, J. R., \& Aguinis, H. (2013). The too-much-of-a-good-thing effect in management.

4

Sánchez-Manzanares, M., Rico, R., Gil, F., \& Martín, R. S. (2006). Memoria transactiva en equipos de toma de decisiones: Implicaciones para la efectividad de equipo. $=$ Transactive memory in decision-making teams: Implications for team effectiveness. Psicothema, 18, 750-756. doi:10.1177/0013164409344520

Schmitt, N., \& Kuljanin, G. (2008). Measurement invariance: Review of practice and implications. Human Resource Management Review, 18, 210-222

Schumacker, R. E., \& Lomax, R. G. (1996). A guide to structural equations modeling. Hillsdale, NJ: Erlbaum.

Short, S. E., Sullivan, P., \& Feltz, D. L. (2005). Development and preliminary validation of the collective efficacy questionnaire for sports. Measurement in Physical Education and Exercise Science, 9, 181-202. doi:10.1207/s15327841mpee0903_3.

Spink, K. S. (1990). Group cohesion and collective efficacy of volleyball teams. Journal of Sport Exercise Psychology, 12, 301-311. doi:10.1123/jsep.12.3.301

Wegner, D. M., Erber, R., \& Raymond, P. (1991). Transactive memory in close relationships. Journal of Personality and Social Psychology, 61, 923-929. doi:10.1037/00223514.61.6.923

Williamson, K., \& Cox, R. (2014). Distributed cognition in sports teams: Explaining successful and expert performance. Educational Philosophy and Theory, 46, 640-654. doi:10.1080/00131857.2013.779215 
Running head: COHESION, TRANSACTIVE MEMORY, COLLECTIVE EFFICACY 28

Table 1

Means, standard deviations, intraclass correlation coefficients, correlations, and Cronbach's alpha's

\begin{tabular}{lccccccccc}
\hline & $M(S D)$ & ICC & 1 & 2 & 3 & 4 & 5 & 6 & 7 \\
\hline 1. GI-S & $6.63(1.85)$ & .21 & .85 & & & & & \\
2. GI-T & $7.11(1.69)$ & .14 & $.60^{* * *}$ & .86 & & & & & \\
3. ATG-S & $6.82(1.73)$ & .25 & $.53^{* * *}$ & $.62^{* * *}$ & .83 & & & & \\
4. ATG-T & $6.79(1.66)$ & .15 & $.31^{* * *}$ & $.38^{* * *}$ & $.45^{* * *}$ & .78 & & & \\
5. Cohesion & $6.84(1.35)$ & .23 & $.79^{* * *}$ & $.83^{* * *}$ & $.83^{* * *}$ & $.67^{* * *}$ & .89 & & \\
6. TMS & $3.91(0.57)$ & .27 & $.40^{* * *}$ & $.55^{* * *}$ & $.68^{* * *}$ & $.51^{* * *}$ & $.68^{* * *}$ & .89 & \\
7. Collective efficacy & $3.55(0.64)$ & .25 & $.32^{* * *}$ & $.40^{* * *}$ & $.52^{* * *}$ & $.41^{* * *}$ & $.53^{* * *}$ & $.62^{* * *}$ & .81
\end{tabular}
Note. ${ }^{*} p<.05 ;{ }^{* *} p<.01{ }^{* * *} p<.001$. Cronbach's alpha coefficients are on the diagonal. GI-S $=$ Group Integration-Social, GI-T = Group Integration-Task, ATG-S = Individual Attraction to the Group-Social, ATG-T = Individual Attraction to the Group-Task, and TMS = Transactive memory systems. 


\section{Hypothesized model 1}

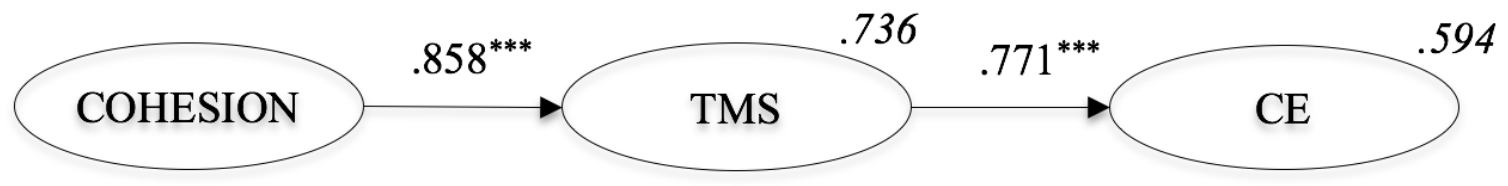

\section{Alternative model 1}

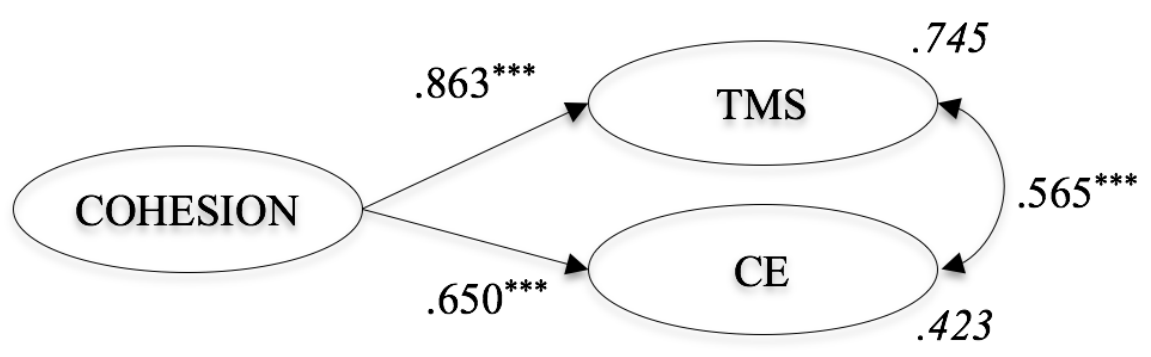

Figure 1. Hypothesised models of group processes.

Note. ${ }^{* * *} p<.01$. Standardized coefficients are presented and proportions explained variance are presented in italics. TMS $=$ Transactive memory systems, and CE $=$ Collective efficacy . 


\section{Hypothesized model 2}

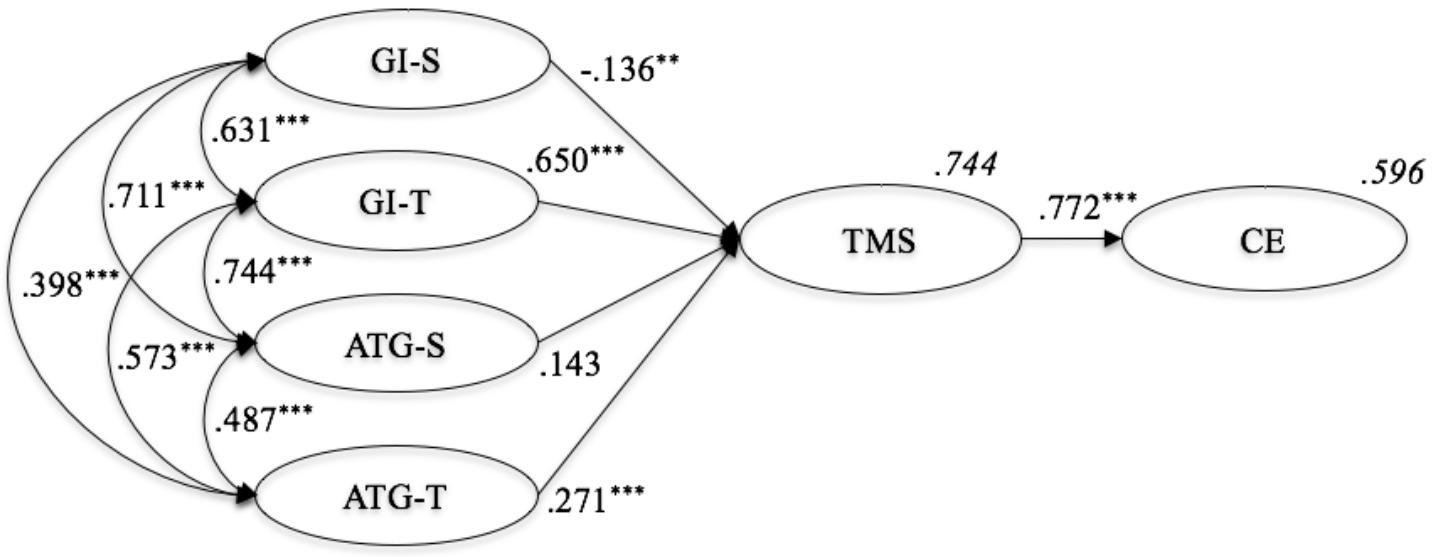

Alternative model 2

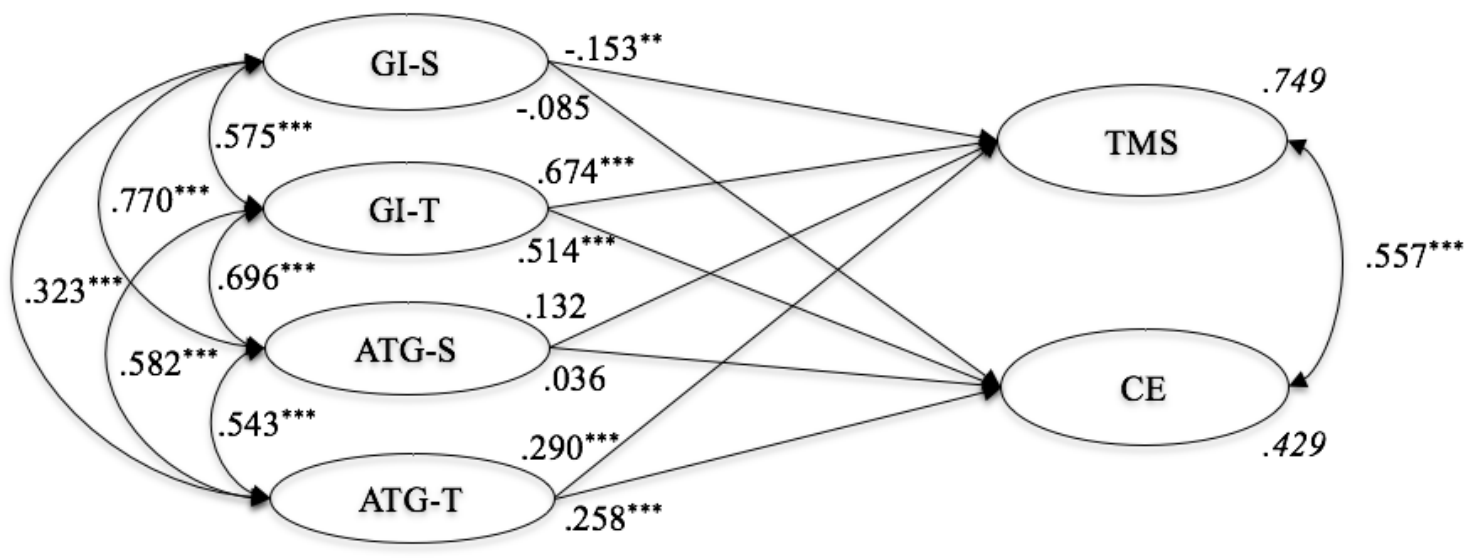

Figure 2. Alternative models of group processes.

Note. ${ }^{* * *} p<.01$. Standardized coefficients are presented and proportions explained variance are presented in italics. GI-S = Group Integration-Social, GI-T = Group Integration-Task, ATG-S = Individual Attraction to the Group-Social, ATG-T = Individual Attraction to the Group-Task, and TMS = Transactive memory systems, and CE = Collective efficacy. 